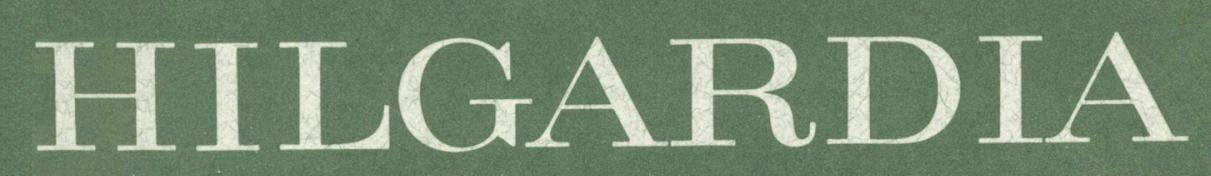

A JOURNAL OF AGRICULTURAL SCIENCE PUBLISHED BY THE CALIFORNIA AGRICULTURAL EXPERIMENT STATION

Volume 39, Number $21 \cdot J u l y, 1969$

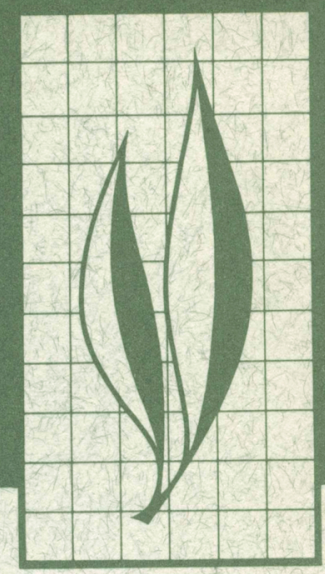

\title{
Mycotoxins of Entomophthoraceous Fungi
}

Sothorn Prasertphon and Y. Tanada 


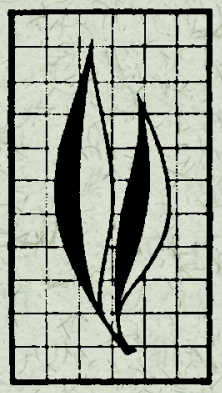

Among the four entomophthoraceous species, Entomophtbora coronata, E. apiculata, E. thaxteriana, and $E$. virulenta, only the first two species produced culture filtrates that were toxic when inoculated into the hemocoels of the larvae of seven insect species. The culture filtrates, however, produced no apparent toxicity when fed to the larvae of Galleria mellonella. The fungi produced mycotoxins in all media suitable for their growth in vitro and in vivo. The mycotoxins produced by the two fungi had similar properties and appeared to be identical, but $E$. coronata produced much more toxin than E. apiculata in the same period of time. More toxin were produced by both fungi in shake than in stationary cultures. The median effective doses $\left(E_{50}\right)$ of the culture filtrates (96-hour cultures) were estimated from data.

The mycotoxin was not chemically identified, but tests indicated that it was a protein of small molecular weight. The mycotoxin caused a characteristic blackening sign in inoculated larva of $\mathrm{Gal}$ leria mellonella; it also inhibited metamorphosis and affected larval feeding. These signs and symptoms varied among the seven insect species. The mycotoxin also inhibited bacterial growth in dead G. mellonella larva.

In Galleria mellonlela larva, the mycotoxin apparently altered the staining properties of the hemolymph and caused the clumping and coagulation of the hemocytes. Silk gland cells also showed pathologies, but other tissues and organs appeared to be unaffected. Blood color changes and clumping of the hemocytes did not occur in fungus-infected larvae.

\section{THE AUTHORS:}

Sothorn Prasertphon, formerly graduate student in Berkeley, is now Associate Entomologist, Entomology Section, Plant Industry Division, Department of Agriculture, Bangkhen, Bangkok, Thailand.

Y. Tanada is Professor of Entomology and Insect Pathologist, Agricultural Experiment Station, Berkeley. 


\section{Mycotoxins of Entomophthoraceous Fungi ${ }^{1}$}

\section{INTRODUCTION}

Microorganisms are known to produce substances that are toxic to insects. Because some of these substances are not only specific, but nontoxic or only slightly toxic to warm-blooded animals, they offer promise for the control of insect pests. Interest in these toxic substances has increased greatly in the past ten years, as the inadequacies of highly toxic, nonspecific chemical insecticides have become apparent. The microbial toxins have been isolated from various microorganisms, such as fungi and bacteria. In the present study, we have investigated the production of toxins by entomophthoraceous fungi. A preliminary note of this study was published by Prasertphon (1967b).

"Toxin" has been defined by Ludwig (1960) as "a product of a microorganism or microorganism-host interaction which acts directly on living host protoplasts to influence either the course of disease development or symptom expression." "Mycotoxin" is a "toxin produced by fungi" (Forgacs et al., 1962). The term "mycotoxicosis" has been defined as "poisonings of the host which follow entrance into the body of toxic substances of fungal origin" (Forgacs and Carll, 1962). According to Roberts (1964), some toxic substances of fungi are known to be nonproteinaceous and nonantigenic.

Although mycotoxins that affected vertebrates were known over a century ago, such toxins were reported for in- sects less than 50 years ago. In a culture filtrate of a fungus in the Aspergillaceae, Toumanoff $(1928,1931)$ detected a toxin that acted on honey bees. Burnside (1930) extracted an ether-soluble substance from a culture of Aspergillus flavus Link and found it toxic to bees. Dresner (1949) reported that germinating spores of Beauveria bassiana (Balsamo) Vuillemin secreted a substance which, when applied to house flies, produced a "knock-down" effect by rapid paralysis and caused death. This substance was also toxic to the dock beetle (Gastroidea cyanea Melsh.) and the potato tuberworm (Gnorimoschema operculella (Zeller)) (Dresner, 1950). This is the only known report of a contact or vapor poison being produced by an entomogenous fungus. Others have attempted to repeat Dresner's work with the same fungus strain, but failed to confirm his results (Steinhaus and Bell, 1953). Acetone extracts were obtained from the culture filtrates of nine species of fungi by Kodaira (1954). He found substances that were poisonous to silkworms from the cultures of Aspergillus ochraceus Wilhelm and Sterigmatocystis japonica Aoki. In 1959, he investigated seven species of muscardine fungi: Beauveria bassiana, Spicaria pracina (Maubli) Aoki, Isaria farinosa (Dickson) Fries (two strains), Isaria rosea Wize, Metarrhizium anisopliae (=Oospora destructor), Aspergillus flavus Link (two strains), and Aspergil-

\footnotetext{
${ }^{1}$ Submitted for publication July 29, 1968.
} 
lus oryzae Wehmer (three strains). Every strain of the seven species produced substances toxic for the silkworm. The strongest toxic substances were produced by Metarrhizium anisopliae.

Beard and Walton (1965) found that the culture filtrate of Aspergillus flavus var. columnaris, when mixed in the medium of the house fly, did not prevent the fly eggs from hatching, but the maggots soon died. They concluded that the fungus produced a toxic substance. Sussman (1952) found that an aqueous suspension of conidia of Aspergillus flavus, when injected into the pupa of the cecropia moth, produced a blackening color in the blood and integument, and concluded that the blackening was caused by polyphenols that reacted with the enzyme tyrosinase in the blood. $\mathrm{He}$ did not ascertain, however, whether the polyphenols were produced by the fungus or by the autolysis of the insect protein.

The entomogenous fungi are also capable of producing toxins in vivo. Schaerffenberg (1957) reported that Beauveria bassiana produced a mycotoxin in the infected larva of the cockchafer, Melolontha melolontha (Linnaeus). An acetone extract of the macerated tissues of the infected cockchafer larva also killed the larva of the Colorado potato beetle, Leptinotarsa decemlineata (Say), when it was fed potato leaves that had been dipped in the extract. In 1960, Kodaira investigated the in vivo production of toxins in silkworm larvae infected separately by nine species of fungi, including Aspergillus ochraceus and Sterigmatocystis japonica. In every case, he found that the chloroform or ether extracts of the blood of the silkworm in the state of death produced toxic symptoms when injected into a healthy silkworm and concluded that the toxic substances were produced in the blood.

If mycotoxins are to serve as insecticides (Tanada, 1967), then the toxins must be isolated and identified. Thus far, only a few attempts have been made. Kodaira (1961) extracted and purified the toxic substances from the fungus filtrates of Metarrhizium anisopliae, and named them "destruxin ' $A$ ' and ' $B$ '." Apparently, a similar toxic substance was isolated from the culture of Metarrhizium anisopliae by Roberts (1964, $1966 a, 1966 b)$. This substance caused tetanic paralysis in the larvae of Galleria mellonella (Linnaeus) and of Bombyx mori (Linnaeus) when injected into the hemocoel. Cunningham et al. (1951) isolated cordycepin $\left(\mathrm{C}_{10} \mathrm{H}_{13} \mathrm{O}_{3} \mathrm{~N}_{5}\right)$ from the fungus filtrate of Cordyceps militaris (Linnaeus) Link, and observed that it inhibited the growth of many strains of Bacillus subtilis. Cordycepin formed needle-shaped crystals in alcohol and water. Bentley, Cunningham, and Spring (1951) attempted the isolation and structural determination of cordycepin. Kredich and Guarino (1961 $a, b)$ succeeded in isolating homocitrullylaminoadenosine from the fungus filtrate of Cordyceps militaris and studied its biosynthesis, and later its identification (Guarino and Kredich, 1963). Unfortunately, this material was not tested on insects.

Two compounds- $\mathrm{C}_{29} \mathrm{H}_{40} \mathrm{O}_{9}$ (mol. wt. 492) and $\mathrm{C}_{49} \mathrm{H}_{64} \mathrm{O}_{16}$ (mol. wt. 903)were isolated from the culture filtrate of the fungus, Myrothecium roridum Tode, by Kishaba et al. (1962). These compounds inhibited the feeding activity of larvae of the Mexican-bean beetle, Epilachna varivestis Mulsant. According to White and Downing (1947) and Roberts (1964), Myrothecium and Metarrhizium are identical in morphology but may be distinguished by the fact that Myrothecium can digest cellulose. 


\section{MATERIALS AND METHODS}

\section{Fungi, insect species, and their culture}

Four species of Entomophthora were used in the study, including three strains of $E$. coronata (Costantin) Kevorkian. The culture for the Hall strain was obtained from Dr. I. M. Hall who, along with Dietrick (1955), isolated it from the spotted alfalfa aphid, Therioaphis maculata (Buckton). Another strain, NRRL No. 1912, was sent to the Division of Invertebrate Pathology, University of California, Berkeley, by Dr. Hall, who obtained it from Dr. C. W. Hesseltine's culture collection, Northern Utilization Research and Development Division, U.S. Department of Agriculture, Peoria, Illinois. It was apparently isolated by G. W. Martin in July, 1923, from dead wood and contaminated leaves being used in the isolation of myxomycetes (Martin, 1925, and personal correspondence).

Entomophthora apiculata (Thaxter) Gustafsson was received from the Northern Utilization Research and Development Division, and is listed in their collection as NRRL No. 1626. Entomophthora thaxteriana (Petch) Hall and Bell was originally isolated from the spotted alfalfa aphid, Therioaphis maculata, by Hall and Dietrick (1955) and was named $E$. ignobilis by Hall and Dunn (1957), but later found to be a synonym of $E$. thaxteriana (Hall and Bell, 1963). Entomophthora virulenta Hall and Dunn was isolated from the spotted alfalfa aphid. Both $E$. thaxteriana and $E$. virulenta were obtained from Dr. Hall.

All fungus stock cultures were established on slants made of Sabouraud's dextrose agar plus yeast extract, and stored at room temperature $\left(22^{\circ}\right.$ to $27^{\circ} \mathrm{C}$ ). The compositions of the fungus culture media used in the tests were as follows:
(1) Modified* Sabouraud's Dextrose with Yeast Extract (SDAY)

Neopeptone (Difco) ......... $10 \mathrm{gm}$

Bacto-Dextrose ...........4 $40 \mathrm{gm}$

Bacto-Agar .............. $15 \mathrm{gm}$

Yeast Extract ............ 2 gm.

Distilled water (added

until $1,000 \mathrm{ml}$ )........ 1,000 ml

(2) Modified* Peptone Medium with

Glucose (MPTG) (liquid medium)

Bactopeptone (Difco) ....... $10.0 \mathrm{gm}$

Dipotassium phosphate ....... $4.3 \mathrm{gm}$

Potassium biphosphate ....... $3.4 \mathrm{gm}$

Glucose .............. $5.0 \mathrm{gm}$

Distilled water (added

until 1,000 ml) ......... 1,000 ml

(3) Modified* Peptone Medium without Glucose (MPT) (liquid medium)

Bactopeptone (Difco) ...... $10.0 \mathrm{gm}$

Dipotassium phosphate ....... $4.3 \mathrm{gm}$

Potassium biphosphate ...... $3.4 \mathrm{gm}$

Distilled water (added

until $1,000 \mathrm{ml}) \ldots \ldots \ldots \ldots 1,000 \mathrm{ml}$

* Formulas were modified from those provided by Difco (1953).

The cultures of Entomophthora species were stored in air-tight test tubes (Prasertphon, 1967a). Each tube, $18 \times$ $150 \mathrm{~mm}$, contained $10 \mathrm{ml}$ of Sabouraud's dextrose agar with 0.2 per cent yeast extract (SDAY). A rubber "snap cap" (Pyrex), $18 \times 25 \mathrm{~mm}$, was used to cap the test tube instead of the usual cotton plug or metal cap; special precaution was taken to ensure that the inoculated tube was completely sealed and airtight. The tubes of fungus culture were stored vertically at room temperature. Viability was maintained for more than two years.

The strain of the greater wax moth, Galleria mellonella, had been carried through at least three generations from a single parental pair. The insects were reared at $30^{\circ} \pm 1.5^{\circ} \mathrm{C}$ on the medium developed by Roberts (1964). The larvae of the yellow Hungarian strain of the silkworm were reared on fresh leaves of mulberry, Morus alba Linnaeus. The codling-moth larvae, Carpo- 
capsa pomonella (Linnaeus), and the corn-earworm larvae, Heliothis zea (Boddie), were reared on a modifiedartificial diet (Ignoffo, 1963, 1965). The cecropia-moth caterpillars, Hyalophora cecropia (Linnaeus), were reared on fresh leaves of ceanothus. The larvae of the variegated cutworm, Peridroma saucia (Hübner), and of the armyworm, Pseudaletia unipuncta (Haworth), were reared on a modified-artificial diet (Shorey, 1963; Shorey and Hale, 1965).

The stationary cultures of Entomophthora were maintained in $50 \mathrm{ml}$ of a modified peptone liquid medium without glucose (MPT) held in a 250-ml Erlenmeyer flask. The inoculated flask was capped with aluminum foil to prevent contamination, and incubated at room temperature without shaking.

The shake cultures were inoculated and handled in the same manner as those for the stationary cultures, except that they were incubated on a shaker (Gyrotory Shaker, Model G-10, New Brunswick Scientific Company, New Brunswick, New Jersey). The cultures were continuously shaken at 160 oscillations per minute for 96 hours at room temperature $\left(22^{\circ}\right.$ to $\left.27^{\circ} \mathrm{C}\right)$.

\section{Mycotoxin production}

The production of mycotoxin in vitro was investigated with shake fungus cultures. The fungus mycelia in the 96 -hour shake cultures were separated from the fungus filtrate by filtering first through filter paper, and then through a filter membrane $4 \mathrm{~mm}$ in diameter, pore size $0.45 \mu$, under suction. The entire process was carried out in an ultravioletsterilized room. The fungus filtrate was stored in a 20-ml sterilized test tube covered with a bakelite screw cap and kept at $4^{\circ} \mathrm{C}$.

The production of mycotoxin in vivo was established as follows: After the cultures of $E$. coronata and E. apiculata were grown on Sabouraud's dextrose agar plus yeast extract in petri dishes for four days, five wax-moth larvae were introduced into each of the cultures for 24 hours. Then the larvae were transferred to petri dishes whose bottoms were lined with moist filter paper. After four days, 20 larvae in the moribund stage were washed in sterile, distilled water, dried, weighed $(3.30 \mathrm{gm})$, and triturated in a sterile porcelain mortar. Seven $\mathrm{ml}$ of sterile distilled water were added to the triturated larvae, and the mixture was stored at $4^{\circ} \mathrm{C}$ for 24 hours. The suspension was then filtered first through a No. 2 Whatman filter paper, and subsequently through a millipore filter membrane, pore size $0.45 \mu$ in diameter. The final filtrate $(2 \mathrm{ml})$ was injected into the hemocoels of wax-moth larvae for the observation of toxic symptoms. The control larvae were treated in a similar manner, except that they were injected with the filtrate obtained from triturated uninfected larvae.

\section{Inoculation of Entomophthora filtrates}

The per os inoculation was made with a glass capillary tube attached to a 0.25 ml syringe with a Tuohy Luer-Lok catcher adapter (Martignoni, 1955; 1959). The whole unit was mounted on an Agla microinjector (Burroughs Wellcome \& Co., London). The syringe was previously calibrated with mercury. The larvae were microfed under anesthesia in order to avoid serious traumatic lesions (Martignoni and Steinhaus, 1961).

The intrahemocoelic inoculation was performed with a No. 30 hypodermic needle attached to a $0.25-\mathrm{ml}$ glass syringe mounted on an Agla microinjector. The needle was inserted through the planta of the left member of the third pair of prolegs of the wax-moth larva. The larvae were weighed prior to the inoculations, and ranged from 100 to $190 \mathrm{mgm}$. 


\section{Isolation and properties of mycotoxin}

Roberts' (1964) method was used. Fifty $\mathrm{ml}$ of a 96-hour-old fungus culture were poured into a $200-\mathrm{ml}$ separatory funnel, and an equal amount of anhydrous ether was added. The funnel was shaken vigorously for 30 minutes, and then the ether fraction was separated from the filtrate. The procedure was repeated three times with $50 \mathrm{ml}$ of ether added each time to the fungus filtrate. The final volume of $150 \mathrm{ml}$ of the ether extract was evaporated in a ventilation hood at room temperature for 24 hours. The residue of the ether extract was dissolved in $10 \mathrm{ml}$ of sterile, distilled water for six hours before its injection into the larval hemocoel. The aqueous portion, remaining after ether extraction, was also evaporated in the same manner as the ether fraction, with the residue suspended in water before injection into the larva.

In a second attempt at isolation, the $\mathrm{pH}$ of the fungus filtrates was decreased. Fifty $\mathrm{ml}$ of the fungus filtrate required $45 \mathrm{ml}$ of $0.1 \mathrm{~N} \mathrm{HCl}$ to lower the $\mathrm{pH}$ to 2 from 6.9 . Fifty $\mathrm{ml}$ of anhydrous ether were added and the mixture was vigorously shaken. This procedure was repeated three times. The residue of the ether extraction was suspended in $10 \mathrm{ml}$ of sterile, distilled water and injected into the larvae. The aqueous filtrate portion was treated in the same manner as above and then injected into the larvae.

To separate the mycotoxin from the fungus culture filtrate, $10 \mathrm{ml}$ of the culture filtrate were centrifuged at $1,400 \mathrm{~g}$ $(3,100 \mathrm{rpm})$ for one and two hours in a clinical centrifuge. In a second attempt, $3 \mathrm{ml}$ of the culture filtrate were centrifuged at $25,500 \mathrm{~g}(20,000 \mathrm{rpm})$ for one hour in an ultra-centrifuge, and in a third attempt, at $102,000 \mathrm{~g}(40,000$ rpm) for two hours. The control filtrates were treated in the same manner in each experiment.

The thermal inactivation point of the mycotoxin in the culture filtrates was established by heating the filtrates at various temperatures in thermal tubes (Tanada, 1953). In the first experiment, the filtrates were heated at $40^{\circ}, 60^{\circ}$, and $80^{\circ} \mathrm{C}$ for 10 minutes. Since the mycotoxin was inactivated between $40^{\circ}$ and $60^{\circ} \mathrm{C}$, the second experiment was conducted at $36^{\circ}, 40^{\circ}, 45^{\circ}, 48^{\circ}, 52^{\circ}$, and $60^{\circ} \mathrm{C}$. The toxic activity of heated and unheated samples of the culture filtrates was tested by injection into wax-moth larvae.

Inasmuch as the mycotoxin in the culture filtrates became inactivated after prolonged storage at room temperature, the length of storage required for inactivation was investigated. Culture filtrates obtained after 96 hours were held at $25^{\circ} \mathrm{C}$. Every two days a sample of the culture filtrate was taken from the incubator and injected into larvae.

Ten per cent trichloracetic acid (TCA) was mixed with the culture fil trates to denature and precipitate pro teins in the mycotoxins. The following proportions were used:

(1) $9 \mathrm{ml}$ of fungus-culture filtrate + . $1 \mathrm{ml}$ of TCA $(9: 1)$

(2) $8 \mathrm{ml}$ of fungus-culture filtrate + $2 \mathrm{ml}$ of TCA $(4: 1)$

(3) $9 \mathrm{ml}$ of control MPT filtrate +1 $\mathrm{ml}$ of TCA $(9: 1)$

(4) $8 \mathrm{ml}$ of control MPT filtrate +2 $\mathrm{ml}$ of TCA $(4: 1)$

In addition to the mixtures containing TCA, the fungus-culture filtrates were mixed with MPT filtrates as follows:

(1) $9 \mathrm{ml}$ of fungus-culture filtrate + $1 \mathrm{ml}$ of control MPT filtrate $(9: 1)$

(2) $8 \mathrm{ml}$ of fungus-culture filtrate + $2 \mathrm{ml}$ of control MPT filtrate $(4: 1)$

The toxic properties of these mixtures were determined by injecting them into the hemocoels of Galleria mellonella larvae.

Since the mycotoxin could not be extracted from the culture filtrates with ether, it was considered to be present in 
the aqueous portion of the filtrate. Ten $\mathrm{ml}$ of the filtrate were evaporated in an open petri dish in a ventilated air chamber at room temperature for 24 hours. The control was the residue obtained from evaporating $10 \mathrm{ml}$ of a modified peptone medium in the same manner. The residue of the culture filtrate was first examined under the binocular microscope to observe the type of crystallization, and then it was dissolved in sterile, distilled water before injecting into the larvae of Galleria mellonella to test for toxic reactions.

\section{RESULTS}

\section{Production of mycotoxin in the fungus cultures}

Of the four Entomophthora spp., the culture filtrates of only two species, $E$. apiculata and $E$. coronata (strains Hall and NRRL 1912), contained mycotoxin detectable by injection into the hemocoels of Galleria mellonella larvae. The presence of the mycotoxin was indicated by the blackening of the larval blood (plate 1). Also, growth and metamorphosis were inhibited; larvae did not reach the imaginal stage. The culture filtrate of $E$. thaxteriana and $E$. virulenta, however, apparently did not contain mycotoxins, since the larvae injected with these culture filtrates developed and emerged as adults, just as did the control larvae.

Entomophthora coronata and E. apiculata produced mycotoxin in stationary as well as in shake cultures. The stationary-culture filtrates, however, contained smaller amounts of the mycotoxin than the shake-culture filtrates. A $29.2 \mu \mathrm{l}$ dose of each of the stationary-culture filtrates of $E$. coronata and of $E$. apiculata produced no response or blackening sign, but the same dose from shake cultures resulted in 90 per cent of the larvae showing the blackening sign (table 1 ). Detectable mycotoxin was produced by these two fungi after 36 hours of cultivation, but at 24 hours of cultivation, no toxin was detectable in the culture filtrates.

Entomophthora apiculata and $E$. coronata produced mycotoxin in all of the three media tested: modified pep-

\begin{tabular}{|c|c|c|c|}
\hline \multicolumn{4}{|c|}{$\begin{array}{c}\text { RESPONSES OF } \\
\text { GALLERIA MELLONELLA LARVAE TO } \\
\text { INOCULATIONS OF STATIONARY } \\
\text { AND SHAKE CULTURES OF } \\
\text { ENTOMOPHTHORA SPP. }\end{array}$} \\
\hline \multirow{2}{*}{$\begin{array}{l}\text { Type of } \\
\text { culture* }\end{array}$} & \multirow{2}{*}{ Dose } & \multicolumn{2}{|c|}{$\begin{array}{l}\text { Numbert of larvae } \\
\text { responding to filtrates: }\end{array}$} \\
\hline & & E. coronata & E. apiculata \\
\hline \multirow[t]{4}{*}{ Stationary } & $\begin{array}{c}\mu l \\
29.2\end{array}$ & & \\
\hline & 43.8 & 8 & 7 \\
\hline & 58.4 & 10 & 10 \\
\hline & 73.0 & 10 & 10 \\
\hline \multirow[t]{3}{*}{ Shake } & 29.2 & 9 & 9 \\
\hline & $\begin{array}{l}43.8 \\
58.4\end{array}$ & $\begin{array}{l}10 \\
10\end{array}$ & $\begin{array}{l}10 \\
10\end{array}$ \\
\hline & 73.0 & 10 & 10 \\
\hline
\end{tabular}

* Stationary and shake filtrates of a modified peptone medium were inoculated into the control larvae at a dose of $73.0 \mu \mathrm{l}$. None of the larvae showed symptoms.

73.0 $\mu \mathrm{l}$. None of the larvae showed symptoms.
+ Ten larvae were inoculated at each dosage level. They t Ten larvae were inoculated at each dosage level. They
weighed from 0.130 to $0.230 \mathrm{gm}$ for those inoculated with weighed from 0.130 to $0.230 \mathrm{gm}$ for those inoculated with
the filtrates of $E$. coronata, and 0.130 to $0.240 \mathrm{gm}$ for those inoculated with $E$. apiculata.

tone without glucose, modified peptone plus glucose, and Sabouraud's dextrose medium with yeast extract. Although $E$. thaxteriana and $E$. virulenta also grew in these media, they did not produce any detectable mycotoxin, even when a massive dose of their culture filtrates was injected into the larval hemocoels.

The physical appearance of the fungus mycelia was observed in wet-mount preparations with the compound microscope. Mycelia were still growing and showed no signs of autolysis after 36 hours of cultivation. After 48 hours, autolysis occurred in a small portion of the mycelia. At $60,71,84$, and 96 hours, the mycelia showed increasing signs of autolysis, but some of the mycelia were 

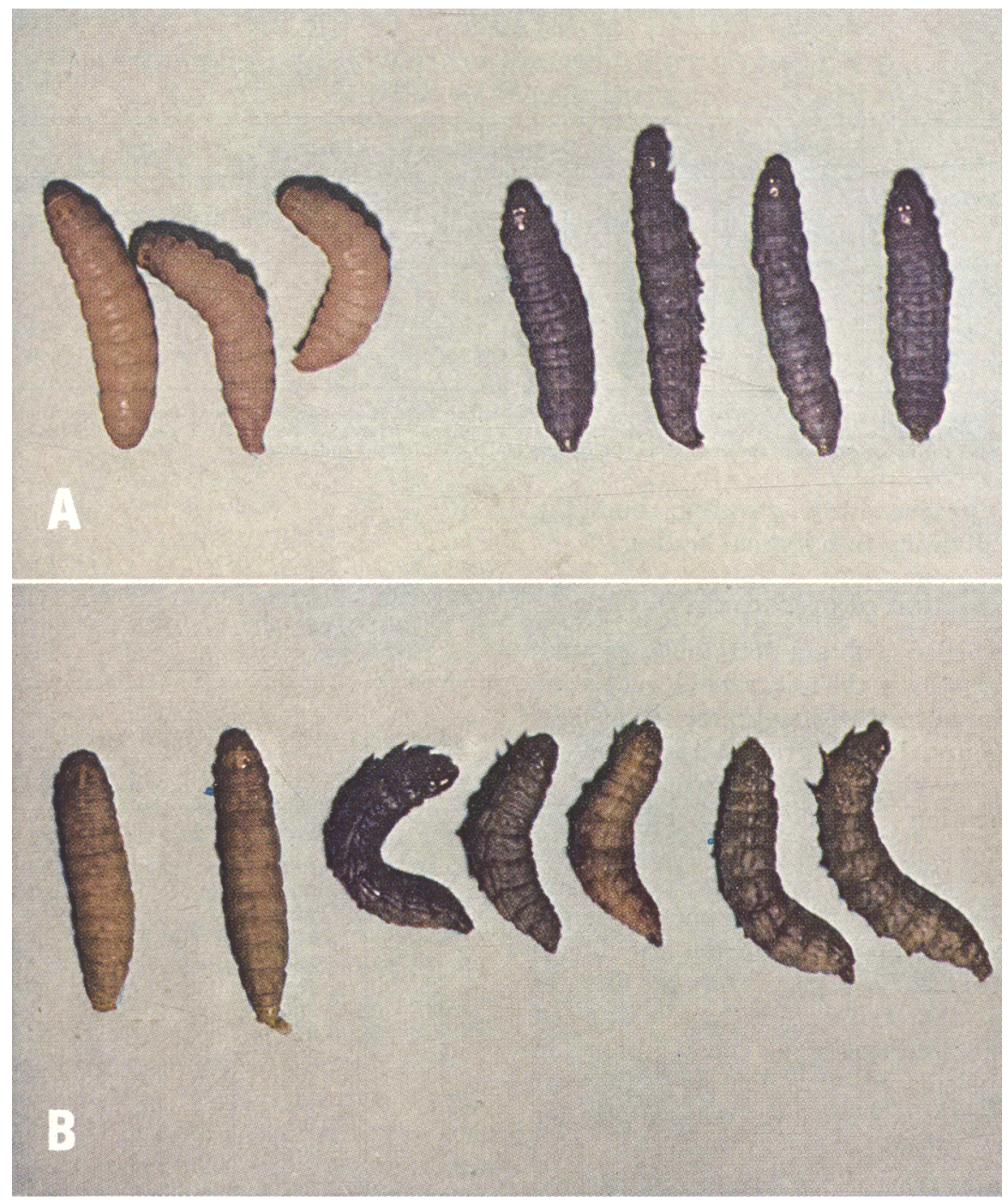

Plate 1. Effect of mycotoxin on larvae of Galleria mellonella. Black larvae in $\mathbf{A}$ (dorsal and lateral views) were injected with culture filtrates of Entomophthora apiculata and those in $\mathbf{B}$ (lateral view) with filtrates of $E$. coronata. Larvae intoxicated by the culture filtrates of both fungi exhibited similar symptoms of blackening and the backward bending of their bodies. Normal pale control larvae in $\mathbf{A}$ and $\mathbf{B}$ were injected with a modified peptone medium. 
TABLE 2

pH VALUES OF THE CULTURE FILTRATES OF DIFFERENT ENTOMOPHTHORA SPECIES

\begin{tabular}{|c|c|c|c|c|c|c|}
\hline \multirow[b]{2}{*}{ Medium* } & \multicolumn{6}{|c|}{$\mathrm{pH}$ values of culture filtrates of: } \\
\hline & $\begin{array}{l}\text { Control } \\
\text { (No fungi) }\end{array}$ & E. apiculata & $\begin{array}{l}E \text {. coronata } \\
\text { strain Hall }\end{array}$ & $\begin{array}{c}\text { E. coronata } \\
\text { strain } \\
\text { NRRL } 1912\end{array}$ & E. thaxteriana & E. virulenta \\
\hline $\begin{array}{l}\text { Control MPT... } \\
\text { Control SDBY. } \\
\text { Filtrate MPT... } \\
\text { Filtrate SDBY. }\end{array}$ & $\begin{array}{l}6.80 \\
5.90 \\
\ldots \\
\ldots\end{array}$ & $\begin{array}{l}\cdots \\
\cdots \\
8.05 \\
5.20\end{array}$ & $\begin{array}{l}\cdots \\
\cdots \\
8.15 \\
5.80\end{array}$ & $\begin{array}{l}\cdots \\
\cdots \\
8.10 \\
6.05\end{array}$ & $\begin{array}{l}\cdots \\
\ldots \\
7.85 \\
6.00\end{array}$ & $\begin{array}{l}\cdots \\
\ldots \\
7.90 \\
5.60\end{array}$ \\
\hline
\end{tabular}

* Control MPT and control SDBY were the filtrates obtained from the modified peptone medium and from the Sabouraud's dextrose medium, respectively, after 96 hours of standing. Filtrates MPT and SDBY were the fungus-culture filtrates of the two media from shake cultures obtained 96 hours after fungus cultivation.

still progressively growing, budding, and dividing into hyphal bodies.

\section{Production of mycotoxin in vivo}

In order to obtain detectable amounts of mycotoxin, the triturated larvae must be stored in the refrigerator for at least 12 hours. If the ground-up larval remains were filtered immediately after trituration, the filtrate produced no response in Galleria mellonella larvae. It appeared that a storage period was required for sufficient amounts of the mycotoxin to diffuse from the larval tissues into the filtrate. Only the filtrates from the triturated fungus-infected larvae produced signs and symptoms in the inoculated larva similar to those of the mycotoxin from the culture filtrates of $E$. coronata and $E$. apiculata. The filtrates from the triturated uninfected larvae did not produce comparable toxic signs.

\section{Properties of the mycotoxin}

$\mathrm{pH}$ values of the culture filtrates varied with the type of culture medium used in growing the fungi (table 2). Use of the modified peptone medium (MPT) resulted in filtrates with higher $\mathrm{pH}$ values than with Sabouraud's dextrose medium (SDBY). When the four species of Entomophthora were grown in the same type of media, the $\mathrm{pH}$ values were nearly the same. Accordingly,
TABLE 3

RESPONSES OF

GALLERIA MELLONELLA LARVAE TO INOCULATIONS OF MYCOTOXIN IN TWO ENTOMOPHTHORA SPP. STORED AT $25^{\circ} \mathrm{C}$

\begin{tabular}{|c|c|c|c|}
\hline \multirow{2}{*}{$\begin{array}{c}\text { Filtrate } \\
\text { storage } \\
\text { period } \\
\left(\text { at } 25^{\circ} \mathrm{C}\right)\end{array}$} & \multirow{2}{*}{ Dose } & \multicolumn{2}{|c|}{$\begin{array}{l}\text { Number of larvae } \\
\text { responding to filtrates of : }\end{array}$} \\
\hline & & E. coronata & E. apiculato \\
\hline days & $\mu l$ & & \\
\hline \multirow[t]{2}{*}{4} & 29.2 & 8 & 9 \\
\hline & 58.4 & 10 & 10 \\
\hline \multirow[t]{2}{*}{6} & 29.2 & 3 & $\mathbf{5}$ \\
\hline & 58.4 & 10 & 10 \\
\hline \multirow[t]{2}{*}{12} & 29.2 & 0 & 0 \\
\hline & 58.4 & 5 & 6 \\
\hline \multirow[t]{2}{*}{14} & 29.2 & 0 & 0 \\
\hline & 58.4 & 6 & 4 \\
\hline \multirow[t]{2}{*}{16} & 29.2 & 0 & 0 \\
\hline & 58.4 & 3 & 3 \\
\hline \multirow[t]{2}{*}{18} & 29.2 & 0 & 0 \\
\hline & 58.4 & 2 & 2 \\
\hline \multirow[t]{2}{*}{20} & 29.2 & 0 & 0 \\
\hline & 58.4 & 1 & 0 \\
\hline \multirow[t]{2}{*}{22} & 29.2 & 0 & 0 \\
\hline & 58.4 & 0 & 0 \\
\hline
\end{tabular}

* Ten G. mellonella larvae were inoculated at each dosage level.

there was no evident relationship between the $\mathrm{pH}$ value of the culture filtrates and the ability to produce mycotoxins by the different species of Entomophthora.

Inasmuch as the culture filtrates of $E$. coronata and $E$. apiculata were unstable when stored at room temperature, their storage at a lower temperature was investigated. At $4^{\circ} \mathrm{C}$ the mycotoxin in 


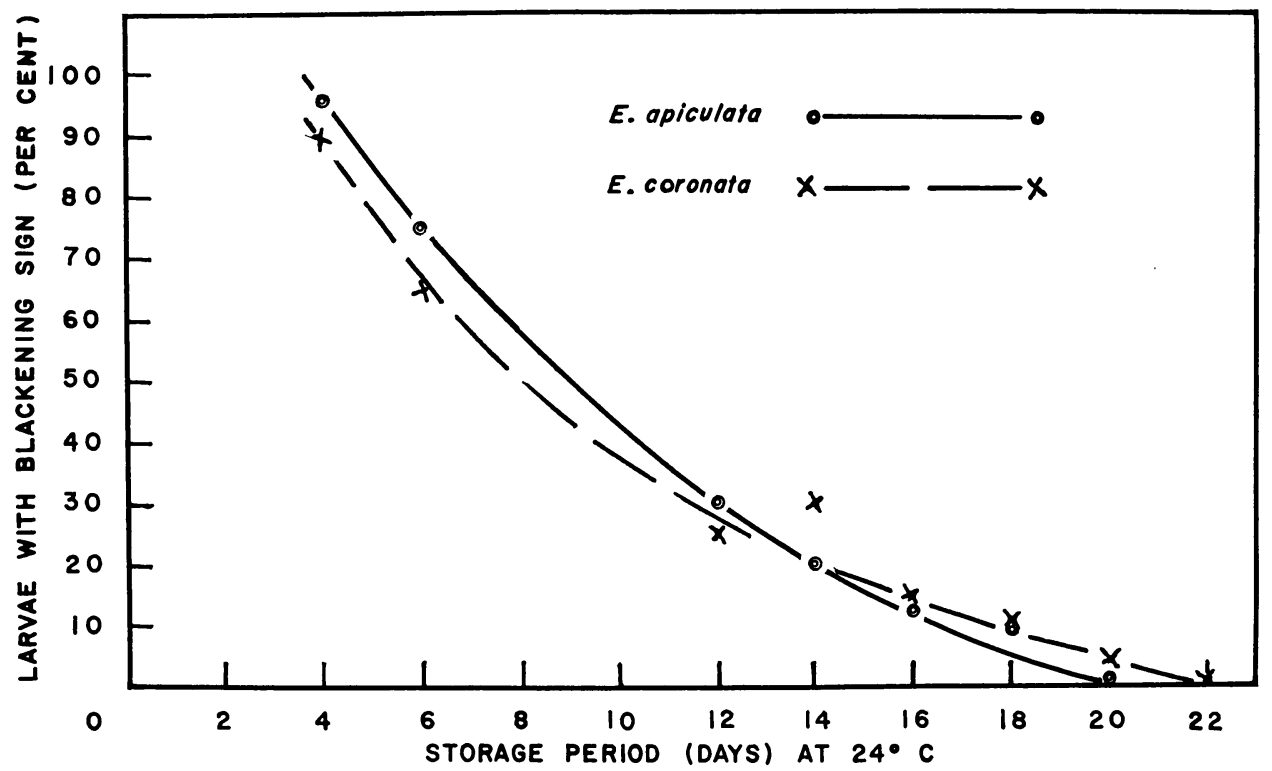

Fig. 1. Effects of storage at $25^{\circ} \mathrm{C}$ on the stability of the mycotoxin produced in the culture filtrates of Entomophthora coronata and E. apiculata. Mycotoxin activity was detected by inoculating the filtrates into the larvae of Galleria mellonella.

the culture filtrates of $\boldsymbol{E}$. coronata and $E$. apiculata retained its activity for 52 weeks, when the test was concluded.

When stored at a constant temperature of $25^{\circ} \mathrm{C}$, the mycotoxin of $E$. coro$n a t a$ was inactivated in 20 to 22 days, and that of $E$. apiculata in 18 to 20 days. The degree of activity of the mycotoxin in the culture filtrates is shown in table 3 and in figure 1. From figure 1, the percentage of inactivation of the mycotoxin could be estimated at different periods of storage at $25^{\circ} \mathrm{C}$.

The results of the thermal tests indicated that the mycotoxin of $E$. coronata and $E$. apiculata was inactivated when heated between $48^{\circ}$ and $52^{\circ} \mathrm{C}$ for 10 minutes.

When the culture filtrates of $E$. coronata and $E$. apiculata at the dose of 240 $\mu \mathrm{l} / \mathrm{gm}$ larval weight were injected into the larvae of $G$. mellonella, they prolonged larval life beyond that of the control larvae and even affected metamorphosis. Silk production and pupation were also affected. Eventually the treated larvae died. (The signs and symptoms produced in these individuals are described later in this paper.) The two culture filtrates also inhibited metamorphosis of Bombyx mori, Carpocapsa pomonella, Hyalophora cecropia, Peridroma saucia, and Pseudaletia unipuncta. Larval feeding of some of these species also was affected.

The degree of inhibition of metamorphosis varied with the dose and insect species. The larvae of Heliothis zea could tolerate a dose of $501.9 \mu \mathrm{l} / \mathrm{gm}$ larval weight, and developed to adults. In contrast, the larvae of $G$. mellonella had a median effective dose $\left(\mathbf{E D}_{50}\right)$ of $72.3 \mu \mathrm{l} / \mathrm{gm}$ larval weight for the culture filtrate of $E$. coronata, and $281.0 \mu \mathrm{l} / \mathrm{gm}$ for the culture filtrate of $E$. apiculata.

Only a few of the black, intoxicated larvae of $G$. mellonella underwent putrefaction. Most became hard and mummified. This suggested that the fungus filtrates had an antibacterial property. To verify this, the culture filtrates were tested on bacteria isolated from the intestines of $G$. mellonella larvae. The fungus filtrates failed to inhibit the 
growth of the bacteria when they were added to nutrient agar inoculated with the bacteria. This experiment should be repeated.

\section{Methods used to determine nature of mycotoxin}

An initial attempt was made with ether to extract the mycotoxin from the culture filtrates of $E$. coronata and $E$. apiculata. The ether extract and water portion were each injected into separate larvae of $G$. mellonella. The mycotoxin remained in the water portion and was not extractable by ether.

Since trichloroacetic acid (TCA) denatures proteinaceous substances and precipitates them out of solution, this acid was applied at $4: 1$ to the fungusculture filtrates and to the modified peptone medium (MPT) to test for the presence of such substances. When the filtrates were separated from the precipitates and injected into the larval hemocoels, the typical blackening sign of intoxication in the blood was absent. On the other hand, the fungus-culture filtrate, when mixed with TCA at the ratio of $9: 1$, which did not cause precipitation, produced intoxication when injected into the larvae. These tests suggested that the proteinaceous substances precipitated by TCA contained the mycotoxin.

Centrifugation of the culture filtrates even at 25,500 $g(20,000 \mathrm{rpm})$ for one hour, and at 102,000 $\mathrm{g}(40,000 \mathrm{rpm})$ for two hours, formed no apparent sediment-indicating that the mycotoxin had a small molecular weight.

Ten $\mathrm{ml}$ of the culture filtrates of Entomophthora species were completely evaporated in about 48 hours at room temperature. The residue was collected and dissolved in $5 \mathrm{ml}$ of sterile, distilled water. The mixture obtained from the filtrates of $E$. coronata and of $E$. apiculata, when injected into the hemocoels of $G$. mellonella larvae, produced intoxication, but those of $E$. thaxteriana and $E$. virulenta caused no apparent toxicity. The mycotoxin, therefore, was not volatilized during the water evaporation.

Large numbers of long, needle-shaped crystals were noted when the culture filtrate residues of $E$. coronata and $E$. apiculata were examined under the binocular dissecting microscope. The crystals were transparent, straight, pointed at both ends, varied in diameter and length, and were visible to the naked eye. They were probably derived from material excreted by the fungi, and might be the mycotoxin. The needleshaped crystals were rare, however, in the culture filtrates of $\boldsymbol{E}$. thaxteriana and $E$. virulenta and in the modified peptone medium. Some crystals, smaller in diameter and shorter in length, were probably crystallized peptone.

\section{Microfeeding of G. mellonella}

Oral microfeeding of the culture filtrates of $E$. coronata and $E$. apiculata did not produce the blackening sign in the larvae of $G$. mellonella, and had no apparent effect, at doses of 29.4, 43.8, 58.4 , and $73.0 \mu \mathrm{l}$ per larva. However, these same doses, when injected into the hemocoels, did produce the blackening sign. Apparently the mycotoxin in these culture filtrates did not pass through the midgut epithelium into the hemocoel, or

Plate 2. A. Effect of mycotoxin on larvae of silkworm, Bombyx mori. Two brownish larvae on right were injected with culture filtrate of Entomophthora apiculata. The normal pale control larva was injected with the filtrate of a modified peptone medium. B. Effect of mycotoxin on pupation of corn earworm, Heliothis zea. Two abnormal prepupae on the right developed from larvae injected with culture filtrate of $E$. apiculata. Normal pupae (left) were from larvae injected with filtrate of modified peptone medium. C. Cecropia caterpillar, Hyalophora cecropia, showing the effect of $E$. coronata mycotoxin six hours after injection. Control larva (left) was injected with filtrate of modified peptone medium and was normal in color. The three intoxicated larvae developed black spots that spread and covered them entirely. 

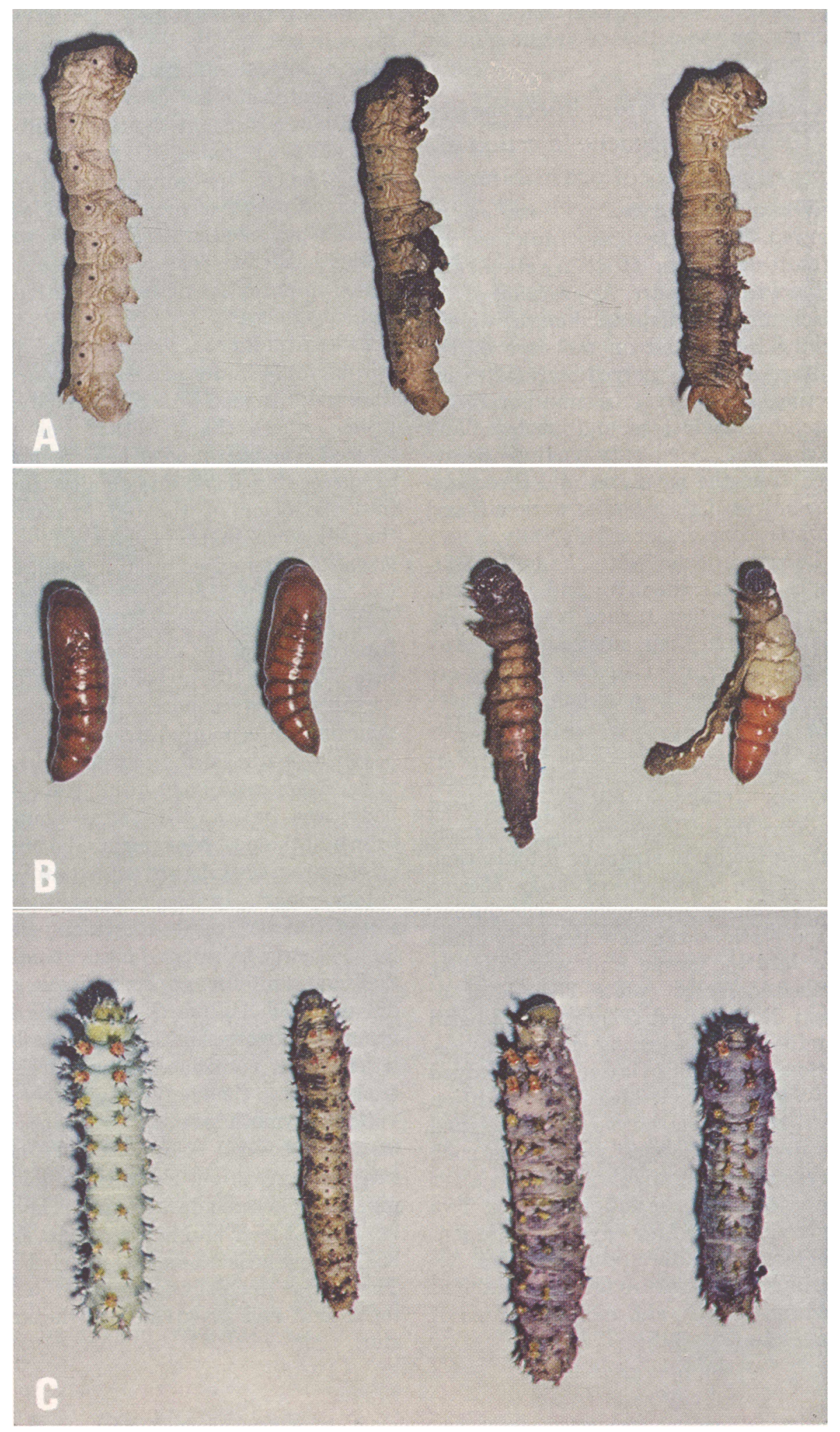
it was destroyed or inactivated in the midgut by the action of enzymes or by a change in $\mathrm{pH}$.

\section{Reactions of different insect species to the intrahemocoelic injection of Entomophthora culture filtrates}

Wax-moth larvae, $G$. mellonella, showed blackening signs within ten minutes to 24 hours after injection, and often within 2 hours. Appearance of the blackening sign depended on the weight of the larvae and on the dose of the culture filtrates. Immediately after injection, some larvae became paralyzed, extended their legs and prolegs, and became stiff. Some only partially recovered from the paralysis, and the posterior halves of their bodies were stiff and slightly bent or arched dorsally.

Larvae injected with the culture filtrates became inactive; and with sufficient dosage they turned black and discharged from their anuses a dark gray coagulated liquid. Often the larvae were glued down at the anal end to the container by this liquid discharge. The blackening sign was first noticeable in the region of the dorsal blood vessel (heart), where it was more pronounced than at other locations in the larvae during the early stages of intoxication. Later, the whole insect body became evenly black (plate 1A). The intoxicated black larvae were less active than the healthy larvae and were slightly arched dorsally (plate 1B). Most of them did not feed. Those that fed still retained the blackening signs.

Some of the intoxicated larvae stayed alive even in their blackened condition until the control larvae had developed to adults. The longest period that such larvae remained alive was 25 days after the injection of the fungus filtrate. Two larvae lived for four days after the control larvae had developed to adults. Accordingly, the culture filtrates inhibited feeding, growth, and metamorphosis of the larvae.
Most of the blackened larvae could not spin silk, but those receiving a small dose of mycotoxin had the ability to spin small amounts of very thin silk. Such larvae died in their thin silk cocoons. If the intoxicated larvae pupated, they died in the pupal stage. After death, only some of the blackened larvae became putrefied; instead, their whole bodies hardened. The toxic culture filtrates apparently possessed antibacterial substances.

Silkworm larvae, Bombyx mori, were still alive 24 hours after injection, but their color turned brown, especially the proleg where the injection was performed. The brown color became darker in succeeding days, and finally turned into the color of the old exuviae of the silkworm larvae (plate 2A). The larvae attempted ecdysis, but the exuviae adhered to their bodies.

In some cases, the silkworms died three days after the injection of the culture filtrates. Their bodies were bent dorsally and were more or less stiff, and their anal ends pointed straight out. The posterior parts of the larvae appeared to be soaked with body fluid. The entire body was brown, with a pronounced brown in the posterior parts. The brown color progressively extended to the anterior part. In other cases, the injected larvae were brownish-yellow. Some newly-injected larvae vomited their gut contents, appeared weak, and did not feed. Unlike $G$. mellonella larvae, the silkworm larvae which received lethal doses continued, in general, to feed for some time before dying.

Codling-moth larvae, Carpocapsa pomonella, changed color within 20 minutes after injection. From their normal pink, they became darker pink. The larvae did not feed, and in some cases, their bodies were twisted and later dried out. The change in color began from the posterior end and progressed to the anterior. 
Corn-earworm larvae, Heliothis zea, were much more resistant to the mycotoxin than were $G$. mellonella. Even a massive dose of the culture filtrates (about $320 \mu \mathrm{l} / \mathrm{gm}$ larval weight) did not cause any color change, as compared to the dose of $190 \mu \mathrm{l} / \mathrm{gm}$ of larval weight that was sufficient to produce the blackening sign in the G. mellonella larva. An $H$. zea larva, injected with a dose of 36 to $116 \mu \mathrm{l} / 0.363-0.590 \mathrm{gm}$ of larval weight, developed normally and emerged to the adult stage, just as the uninjected larvae. However, when larvae were injected with a dose of 146 to $160 \mu \mathrm{l} / 0.363-0.590 \mathrm{gm}$ larval weight, development was arrested; in some cases, the body became black, hard and brittle. The hardened skin, when touched with a pointed metal forceps, was easily broken.

Larvae injected with 146 to $160 \mu \mathrm{l}$ transformed to the pupal stage about two days after the uninjected larvae, but their pupation was incomplete. The posterior part, especially the abdomen, formed pupal skin, but the region from the thorax to the head retained the larval characters. The body was shrunken abdomen (plate 2B). Part of the integument on the dorsal part of the body was that of the pupa, but the ventral integument remained larval in character. The abnormal individual had an enlarged abdomen, with head and throat of larval character, and retained the prolegs, but lacked adult wings, antennae, or legs. The incomplete pupa had white chalky skin at the thoracic region. All of these abnormal individuals died.

Cecropia-moth caterpillars, Hyalophora cecropia, developed the blackening sign from two to eight hours after injection. An injected larva discharged greenish-yellow, and at times reddishbrown, gut contents from its mouth and anus. When it was wounded, its blood was red-orange in color, and in a few minutes, became red-brown. The blood of an uninjected larva was green. Intox- icated larva became more or less inactive, but still fed when the dose of mycotoxin was low.

The first blackening sign appeared at the base of the bristles as black spots, which spread and coalesced into larger spots (plate 2C). The entire bristle stem above the black spot also turned black. Then the prolegs became black. As intoxication progressed, the entire larval body became covered with black spots and left only small patches of green color. The body became flaccid. The larva stopped feeding and died within a day.

Variegated-cutworm larvae, Peridroma saucia, started to change color within five to seven hours after injection, stopped feeding, and died within two days. They became blackish-purple, and the dorsal vessel was only slightly different in color from that of an uninjected larva.

Armyworm larvae, Pseudaletia unipuncta, when injected with the culture filtrates (44 to $58 \mu \mathrm{l} / 0.280$ to $0.590 \mathrm{gm}$ of larval weight), changed from their normal light-brown to a purple color within one-half to two hours. The blood of the injected larva was bright purple in color. The color of the larva turned blackish-purple within three to four hours. The larva which showed purple signs died within one to three days after the injection of the culture filtrates. The dead larva was soft, unlike the dead larva of $G$. mellonella.

\section{Pathology of mycotoxin}

When paraffin sections of an intoxicated (and blackened) larva of $G$. mellonella were treated with Delafield's and counter-stained with Patay's stain, the hemolymph was stained dark-brown, as compared with the light-green color of the hemolymph of an uninjected larva. The blood cells of the injected larva were aggregated into clumps, with a clear zone surrounding each nucleus. 


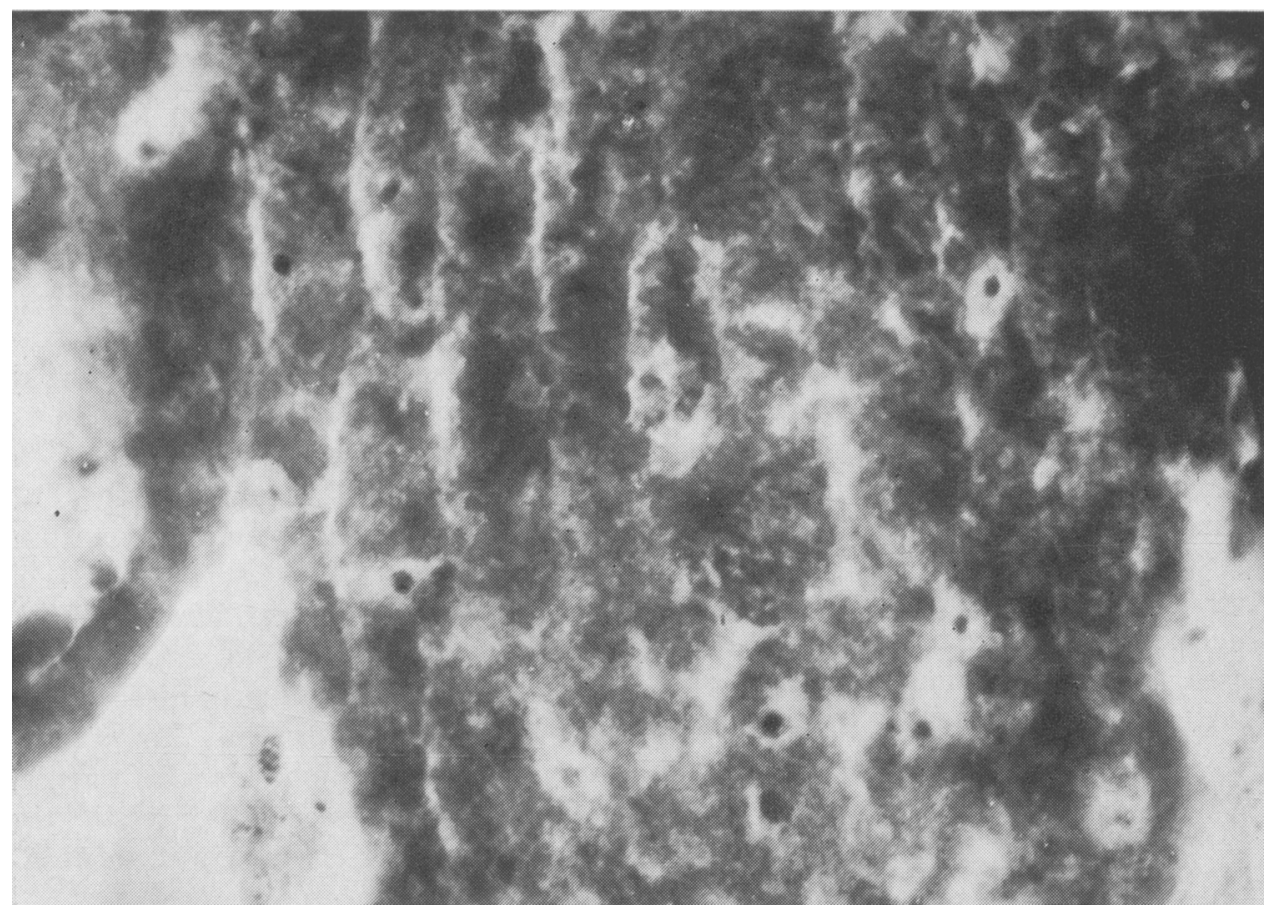

Fig. 2. Section through a larva of Galleria mellonella which had blackened after the injection of the culture filtrate of Entomophthora coronata, showing clumped, coagulated blood cells whose nuclei were stained darkly and surrounded by clear zones. Section stained with Delafield's hematoxylin and counterstained with Patay's stain. 960X.

TABLE 4

DATA FROM WHICH MEDIAN EFFECTIVE DOSES (ED ${ }_{50}$ ) OF THE CULTURE FILTRATES OF TWO ENTOMOPHTHORA SPP. WERE ESTIMATED FOR LARVAE OF GALLERIA MELLONELLA

\begin{tabular}{|c|c|c|c|c|c|c|}
\hline \multirow[b]{2}{*}{ Dose* } & \multicolumn{3}{|c|}{ E. coronata filtrate $\dagger$} & \multicolumn{3}{|c|}{ E. apiculata filtrate } \\
\hline & $\begin{array}{l}\text { Time lapse } \\
\text { before larvae }\end{array}$ & Larvae & oonding & $\begin{array}{l}\text { Time lapse } \\
\text { before larvae }\end{array}$ & Larvae & onding \\
\hline$\mu l$ & Hours & Number & Per cent & Hours & Number & Per cent \\
\hline $25.55 \ldots \ldots$ & $\ldots \ldots$ & 0 & 0 & $0.37-1.54$ & 3 & 15 \\
\hline $29.20 \ldots$ & $\ldots$ & 0 & 0 & $2.10-2.55$ & 6 & 30 \\
\hline $32.85 \ldots$ & 12.40 & 1 & 5 & $0.20-3.47$ & 12 & 60 \\
\hline $36.50 \ldots$ & 11.00 & 4 & 20 & $0.36-2.77$ & 15 & 75 \\
\hline $40.15 \ldots$ & 10.40 & 6 & 30 & $0.23-4.49$ & 15 & 75 \\
\hline $43.80 \ldots$ & 10.20 & 9 & 45 & $0.30-3.29$ & 16 & 80 \\
\hline $51.10 \ldots \ldots \ldots \ldots \ldots$ & 10.00 & 17 & 85 & $0.35-2.30$ & 20 & 100 \\
\hline control $\neq \ldots \ldots \ldots \ldots \ldots$ & $\ldots \ldots$ & 0 & $\mathbf{0}$ & $\ldots \quad \ldots$ & 0 & 0 \\
\hline
\end{tabular}

* Twenty larvae were inoculated at each dosage level. Larvae weighed from 0.120 to $0.180 \mathrm{gm}$ for those inoculated with $E$. coronata filtrate, and from 0.130 to $0.180 \mathrm{gm}$ for those inoculated with $E$. apiculata filtrate.

$\dagger$ The filtrate of only $E$. coronata was diluted with the modified peptone medium at 1 part filtrate to 3 parts modified peptone medium.

$\ddagger$ Inoculated with culture filtrate of modified peptone medium. Larvae did not show any color change. 


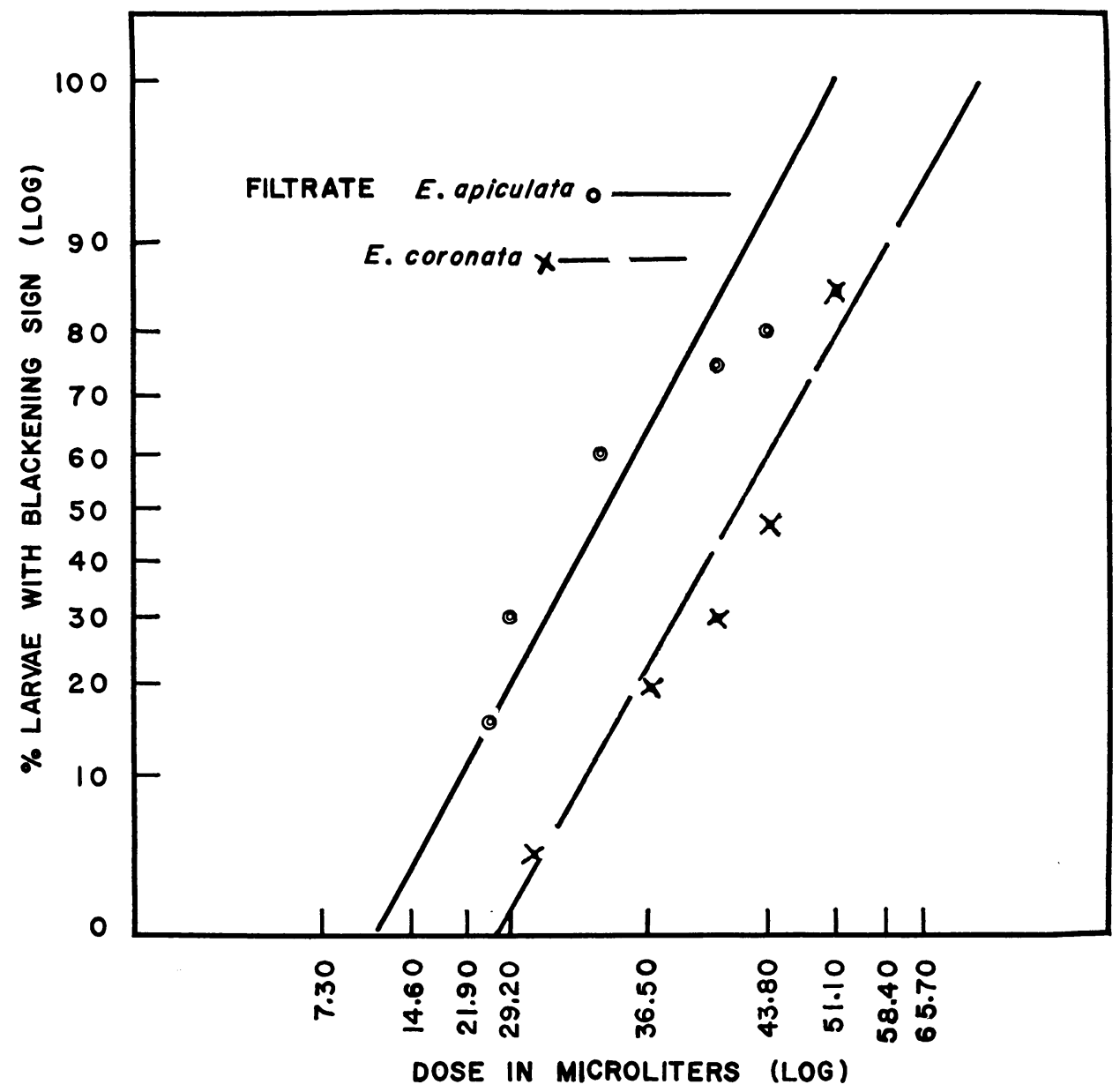

Fig. 3. Estimation of median effective dose $\left(\mathrm{ED}_{50}\right)$ of mycotoxin produced in culture filtrates of Entomophthora coronata and $E$. apiculata. Data were obtained from table 4. Filtrate of $E$. coronata was diluted with modified peptone medium at one part filtrate to three parts modified peptone medium (MPT).

The nucleus stained deeply with Heidenhain's iron hematoxylin. The cytoplasm of the blood cells stained darkbrown, and the borderline of each cell could not be differentiated in the clump of blood cells. The mixture of blood cells and coagulated hemolymph appeared to be semi-solid (fig. 2). Such aggregation, clumping, and coagulation of the blood cells and hemolymph did not occur in the uninjected larva.

The epithelial cells of the silk glands and reservoirs had a larger number of vacuoles than did those of the unin- jected larva, especially in the areas around the nuclei, whose membranes were indistinct. The nuclear contents shrank and were attached to the vacuolar membranes or disintegrated. Remaining organs and tissues of the intoxicated larva had no detectable abnormalities.

Striking differences were noted between the histopathologies of $G$. mellonella larva injected with mycotoxin and those infected with the two Entomophthora species. The blood did not aggregate and clump or change color in 
the hemolymph of the fungus-infected larvae as it did in the intoxicated larva described above. The fungus-infected larvae did not live for more than three to five days, while the intoxicated larvae lived up to 22 days.

\section{Response to dosage of culture filtrates}

In order to establish the median effective dose $\left(\mathbf{E D}_{50}\right)$, the standard culture filtrates of $E$. coronata and $E$. apiculata were injected at different dosages into the hemocoels of $G$. mellonella larvae. The data of table 4 were plotted on logarithmic paper (fig. 3). Since the original culture filtrate of $E$. coronata was very active (even a small dose of $25.55 \mu \mathrm{l} / 0.120$ to $0.180 \mathrm{gm}$ of larval weight produced a 100 per cent response), it was diluted one part of culture filtrate to three parts of MPT.

$\mathrm{ED}_{50}$ of the culture filtrates obtained by plotting dosage on logarithmic paper was very close to the $\mathrm{ED}_{50}$ obtained by probit analysis (Finney, 1952).

For $E$. coronata culture filtrates, the $\mathrm{ED}_{50}$ (diluted 1 part filtrate to 3 parts MPT) was estimated from the following:

(1) Figure 3 (the graph), $41.64 \mu \mathrm{l} /$ 0.120 to $0.180 \mathrm{gm}$ larval weight;
(2) calculation, $43.65 \mu \mathrm{l} / 0.120$ to $0.180 \mathrm{gm}$ larval weight; and

(3) calculation (for $\mathrm{ED}_{50}$ range), 43.05 to $44.26 \mu \mathrm{l} / 0.120$ to 0.180 gm larval weight.

For E. apiculata culture filtrates, the $\mathrm{ED}_{50}$ was estimated from the following:

(1) Figure 3 (the graph), $33.15 \mu \mathrm{l} /$ 0.130 to $0.180 \mathrm{gm}$ larval weight;

(2) calculation, $32.81 \mu \mathrm{l} / 0.130$ to $0.180 \mathrm{gm}$ larval weight; and

(3) calculation (for $\mathrm{ED}_{50}$ range), 27.06 to $40.65 \mu \mathrm{l} / 0.130$ to 0.180 gm larval weight.

Since the culture filtrate of $\boldsymbol{E}$. coronata had been diluted $1: 3$, the $\mathrm{ED}_{50}$ of of the original culture should be $\frac{41.64}{4}=$ $10.41 \mu \mathrm{l} / 0.120$ to $0.180 \mathrm{gm}$ of larval weight obtained by plotting the dosages on logarithmic paper; and $\frac{43.65}{4}=$ $10.9125 \mu \mathrm{l} / 0.120$ to $0.180 \mathrm{gm}$ of larval weight by probit analysis. The $\mathrm{ED}_{50}$ range should be $\frac{43.50}{4}$ to $\frac{44.26}{4}=10.76$ to $11.06 \mu \mathrm{l} / 0.120$ to $0.180 \mathrm{gm}$ of larval weight.

\section{DISCUSSION}

Out of four entomophthoraceous species which were examined, only two of them, Entomophthora coronata and $\boldsymbol{E}$. apiculata, produced mycotoxins when cultured in vitro and in vivo. The mycotoxins produced by the two fungi appeared to be identical in every respect, but further study is necessary to establish whether only one mycotoxin was involved in our study. Entomophthora coronata, however, produced much more mycotoxin than $E$. apiculata when cultured in liquid medium for the same period of time.

The mycotoxin in the culture filtrates could be detected by injecting the filtrates into the hemocoels of wax-moth larvae (Galleria mellonella). The fungi produced more mycotoxin in shake than in stationary cultures, probably because they grew more rapidly under increased aeration and circulation of the medium. The mycotoxin appeared to be a natural excretory product rather than a product of autolysis of the fungus, because detectable amounts of the mycotoxin were found in fungus cultures after 36 hours, whereas autolysis did not begin until after 48 hours of cultivation. Smith (1953) also observed that autolysis oc- 
curred at the end of 48 hours of culture. However, the peak of mycotoxin production in the filtrate occurred when autolysis was evident, so autolysis might be important in the accumulation of the mycotoxin in the filtrate. This aspect needs further investigation.

The mycotoxin possessed characteristics and properties similar to those of proteinaceous substance, e.g., it was precipitated by 10 per cent trichloroacetic acid. It was heat-labile and lost its activity during storage at room temperature or at $25^{\circ} \mathrm{C}$ for 22 days. Its thermal-inactivation point was between $48^{\circ}$ and $52^{\circ} \mathrm{C}$ for 10 minutes. The mycotoxin could not be sedimented out of the culture filtrates by centrifugation at $102,000 \mathrm{~g}$ for two hours. It was nonether-soluble, but water-soluble and nonvolatile, and appeared to form needleshaped crystals in the residue of fungus-culture filtrates. When the residue was resuspended in water, it still caused intoxication in G. mellonella larvae. Thus far, we have not succeeded in establishing the chemical identity of the mycotoxin.

The mycotoxin, however, was different from "destruxin 'A' and 'B' " which Kodaira (1960) purified from Metarrhizium anisopliae. Destruxin $\mathrm{A}$ and $\mathrm{B}$ were heat-stable and could withstand heating for one hour at $100^{\circ} \mathrm{C}$. They caused tetanic paralysis in injected larvae of Galleria mellonella (Roberts, 1964) and of Bombyx mori (Kodaira, 1960; Roberts, 1964). In our study, this form of paralysis did not occur in larvae inoculated with the mycotoxins of $E$. coronata and $E$. apiculata. Instead, larvae developed blackening signs. Moreover, the fungus-culture filtrates seemed to inhibit the growth of bacteria in dead G. mellonella larvae. This property is similar to that of cordycepin formed by Cordyceps militaris (Cunningham et al., 1951).
When injected in sufficient amounts into the larval hemocoel, the culture filtrates inhibited metamorphosis and altered the feeding habits of some insect species. A lethal dose of the culture filtrates eventually caused the death of the insect in the larval stage or during pupation.

Microfeeding of the culture filtrates of $E$. coronata and $E$. apiculata to $G$. mellonella larvae did not produce any detectable signs or symptoms. The ineffectiveness of the mycotoxin when fed to larvae restricts the application of this toxin as a microbial pesticide on insect pests. Yendol (1964) also failed to intoxicate the eastern subterranean termite, Reticulitermes flavipes, by feeding it the culture filtrate of $E$. coronata. He speculated that (a) the mycotoxin might be a function of the specific host-parasite relationship, (b) the mycotoxin was diluted in the modified peptone medium or sequestered by compounds in the medium, with the result that the filtrates became inactive, or (c) the intestinal wall and integument acted as a barrier to the toxic product.

Intrahemocoelic injections of the culture filtrates of $E$. coronata and $E$. apiculata into seven different insect species showed that the mycotoxin inhibited metamorphosis, molting, and feeding, but there were differences in the reactions among the insect species to the toxin. The Heliothis zea larvae required a much larger dose than the larvae of the other species to produce these signs and symptoms. The blood-color change also varied among the different insect species.

Initially, change in the color of the blood was the most evident sign in the intoxication caused by the mycotoxin. A study of the histopathology of an intoxicated larva of $G$. mellonella showed that the mycotoxin severely affected the hemolymph, changed its staining property 
and caused clumping of the hemocytes. Sussman (1952) found that an aqueous suspension of the conidia of Aspergillus flavus injected into a cecropia pupa caused blackening of the integument and blood. He believed that the blackening was caused by the enzyme tyrosinase, which is almost universally present in insects and is considered to play an important role in their respiration and structural development (Sussman, 1949).

Aside from the blood, the only other tissue or organ exhibiting detectable pathologies was the silk glands. This suggests that the pathological effect of the mycotoxin on the metabolism of the host consists primarily of causing the failure of the hemolymph to circulate the nec- essary nutrients and hormones to the tissues and organs involved in metamorphosis and molting. This aspect needs further study and clarification. Also, the mycotoxin should be compared with known poisons that act on the insect hemolymph.

Although the culture filtrate, and presumably the mycotoxin, when inoculated into the larva caused darkening of the blood and clumping of the hemocytes, the infection by $\boldsymbol{E}$. coronata and $E$. apiculata did not cause blood color changes and clumping of the hemocytes. The histopathology of these different effects should be investigated further, because our study has shown that the mycotoxin is produced by the fungi in infected larvae.

\section{ACKNOWLEDGMENTS}

We wish to express our grateful appreciation to Edward A. Steinhaus, Professor of Organismic Biology, University of California, Irvine, and to Ralph Emerson, Professor of Botany, University of California, Berkeley, for their critical reading of the manuscript. We also wish to thank the Rockefeller Foundation and the Agency for International Development for providing financial support to Sothorn Prasertphon. 


\section{LITERATURE CITED}

BEARD, R. L., and G. S. WALTON

1965. An Aspergillus toxin lethal to larvae of the house fly. Jour. Invertebrate Pathol. 7(4): $522-23$.

Bentley, H. R., K. G. Cunningham, and F. S. Spring

1951. Cordycepin, a metabolic product from cultures of Cordyceps militaris (Linn.) Link. Part II. The structure of cordycepin. Jour. Chem. Soc. 1951:2301-05.

Burnside, C. E.

1930. Fungous diseases of the honey bee. U. S. Dept. Agr. Tech. Bul. No. 149. 43 pp.

Cunningham, K. G., S. A. Hutchinson, W. Manson, and F. S. Spring

1951. Cordycepin, a metabolic product from cultures of Cordyceps militaris (Linn.) Link. Part I. Isolation and characterization. Jour. Chem. Soc. 1951:2299-2300.

DifCo Laboratories

1953. Difeo manual. 9th ed. Difeo Laboratories, Inc., Detroit, Michigan. 350 pp.

DRESNER, E.

1949. Culture and use of entomogenous fungi for the control of insect pests. Contrib. Boyce Thompson Inst. 15(6) :319-35.

1950. The toxic effect of Beauveria bassiana (Bals.) Vuill. on insects. Jour. New York Ent. Soc. 58(4):269-78.

Finney, D. J.

1952. Probit analysis: 2nd ed. Cambridge University Press. 318 pp.

Forgacs, J., and W. T. CARLL

1962. Mycotoxicoses. Advan. Vet. Sci. 7:273-382.

Forgacs, J., H. Kock, W. T. Carli, and R. H. White-Stevens

1962. Mycotoxicoses. I. Relationship of toxic fungi to moldy-feed toxicosis in poultry. Avian Diseases 6(3):362-80.

Guarino, A. J., and N. M. Kredich

1963. Isolation and identification of $3^{\prime}$-amino-3'-deoxyadenosine from Cordyceps militaris. Biochim. Biophys. Acta. 68(2):317-19.

HALL, I. M., and J. V. BELL

1963. The synonymy of Empusa thaxteriana Petch and Entomophthora ignobilis Hall and Dunn. Jour. Insect Pathol. 5(2) :182-86.

HALL, I. M., and E. J. Dietrick

1955. Fungi on spotted alfalfa aphid. Calif. Agr. 9(12):5, 16.

Hall, I. M., and P. H. DunN

1957. Entomophthorous fungi parasitic on the spotted alfalfa aphid. Hilgardia 27(4):159-81. IGNOFFo, C. M.

1963. A successful technique for mass-rearing cabbage loopers on a semisynthetic diet. Ann. Entomol. Soc. Amer. 56 (2):178-82.

1965. The nuclear-polyhedrosis virus of Heliothis zea (Boddie) and Heliothis virescens (Fabricius). II. Biology and propagation of diet-reared Heliothis. Jour. Invertebrate Pathol. $7(2): 217-26$.

Kishaba, A. N., D. L. Shankland, R. W. Curtis, and M. C. Wilson

1962. Substances inhibitory to insect feeding with insecticidal properties from fungi. Jour. Econ. Ent., 55(2):211-14.

KODAIRA, Y.

1954. Studies on the toxic substances produced by muscardine fungi. I. On the silkworm poisonous substances produced by Asperigillus ochraceus and Sterigmatocystis japonica. (Summary in English.) Res. Rept. Fac. Textile Sericult. Shinshu Univ. No. 4, pp. 47-49.

1959. Studies on the toxic substances produced by muscardine fungi. II. The productivity of the toxic substances of various muscardine fungi in the culture media. (Summary in English.) Res. Rept. Fac. Textile Sericult., Shinshu Univ. No. 9, pp. 79-82.

1960. Studies on the toxic substances produced by muscardine fungi. III. Existence of the toxic substances in the blood of silkworms attacked by various muscardine fungi. (Summary in English.) Res. Rept. Fac. Textile Sericult., Shinshu Univ. No. 10, pp. 130-34.

1961. Biochemical studies on the muscardine fungi in the silkworms, Bombyx mori. Jour. Fac. Textile Sericult., Shinshu Univ., Ser. E. 29:1-68.

Kredich, N. M., and A. J. Guarino

1961a. Homocitrullylaminoadenosine, a nucleoside isolated from Cordyceps militaris. Jour. Biol. Chem. 236 (12):3300-02. 
$1961 b$. Studies on the biosynthesis of cordycepin. Biochim. Biophys. Acta. 47(3):529-34.

Ludwig, R. A.

1960. Toxins. In: Plant Pathology, An advanced treatise, Chapter 9, Vol. 2, pp. 315-57. New York: Academic Press.

Martignoni, M. E.

1955. Microinjector needle for determination of per os- $\mathrm{LD}_{50}$ of insect viruses. Science $122(3173): 764$.

1959. Preparation of glass needles for microinjection. Jour. Insect Pathol. 1(3) :294-96.

Martignoni, M. E., and E. A. Steinhaus

1961. Laboratory exercises in insect microbiology and insect pathology. Minneapolis, Minn.: Burgess Publishing Co., 75 pp.

Martin, G. W.

1925. Morphology of Conidiobolus villosus. Bot. Gaz. $80(3): 311-18$.

Prasertphon, S.

1967a. A practical method for the storage of some Entomophthora species. Jour. Invertebrate Pathol. 9(1):140-42.

1967b. Mycotoxin production by species of Entomophthora. Jour. Invertebrate Pathol. 9(2): 281-82.

ROBERTS, D. W.

1964. Production, extraction, and assay of toxic substances from the entomogenous fungus Metarrhizium anisopliae (Metchnikoff) Sorokin. Ph.D. thesis. Univ. of California, Berkeley. $138 \mathrm{pp}$.

1966a. Toxins from the entomogenous fungus Metarrhizium anisopliae. I. Production in submerged and surface cultures, and in inorganic and organic nitrogen media. Jour. Invertebrate Pathol. $8(2): 212-21$.

1966b. Toxins from the entomogenous fungus Metarrhizium anisopliae. II. Symptoms and detection in moribund hosts. Jour. Invertebrate Pathol. 8(2):222-27.

SchAERFFENBERG, B.

1957. Infektions-und Entwicklungsverlauf des insektentötenden Pilzes Beauveria bassiana (Vuill.) Link. Z. Angen. Entomol. 41(2-3):395-402.

SHOREY, H. H.

1963. A simple artificial rearing medium for the cabbage looper. Jour. Econ. Ent. 56(4) : 536-37.

SHOREY, H. H., and R. L. HALE

1965. Mass-rearing of the larvae of nine noctuid species on a simple artificial medium. Jour. Econ. Ent. 58(3):522-24.

Sмiтн, M. C. W.

1953. The nutrition and physiology of Entomophthora coronata (Cost.) Kevorkian. Ph.D. thesis, $91 \mathrm{pp}$. University of Michigan, Ann Arbor.

Steinhaus, E. A., and C. R. Bell

1953. The effect of certain microorganisms and antibiotics on stored-grain insects. Jour. Econ. Ent. 46(4) :582-98

Sussman, A. S.

1949. The functions of tyrosinase in insects. Quart. Rev. Biol. 24(4):328-41.

1952. Studies of an insect mycosis. V. Color changes accompanying parasitism in Platysamia cecropia. Ann. Ent. Soc. Amer. 45(4):638-44.

TANADA, Y.

1953. Description and characteristics of a granulosis virus of the imported cabbageworm. Proc. Hawaiian Ent. Soc. 15(1):235-60.

1967. Microbial pesticides. In: Pest control, biological, physical, and selected chemical methods. Chapter 2, pp. 31-88. New York: Academic Press.

Toumanoff, C.

1928. Au sujet de l'aspergillomycose des abeilles. Compt. Rend. Acad. Sci. Paris 187(7): 391-93.

1931. Action des champignons entomophytes sur les abeilles. Ann. Parasitol. Humaine et Comparée 9(5):462-82.

White, W. L., and M. H. Downing

1947. The identity of "Metarrhizium glutinosum.” Mycologia 39(5):546-55.

YENDOL, W. G.

1964. The pathogenesis of Entomophthora coronata (Costantin) Kevorkian and Entomophthora virulenta Hall and Dunn (Zygomycetes: Entomophthorales) in termites and aphids. Ph.D. thesis. 222 pp. Purdue : Lafayette, Indiana. 
The journal HILGARDIA is published at irregular intervals, in volumes of about 650 to 700 pages. The number of issues per volume varies.

Single copies of any issue may be obtained free, as long as the supply lasts; please request by volume and issue number from:

$$
\begin{aligned}
& \text { Agricultural Publications } \\
& \text { University Hall } \\
& \text { University of California } \\
& \text { Berkeley, California } 94720
\end{aligned}
$$

The limit to nonresidents of California is $\mathbf{1 0}$ separate titles. The limit to California residents is $\mathbf{2 0}$ separate titles.

The journal will be sent regularly to libraries, schools, or institutions in one of the following ways:

1. In exchange for similar published material on research.

2. As a gift to qualified repository libraries only.

3. On a subscription basis- $\$ 7.50$ a year paid in advance. All subscriptions will be started with the first number issued during a calendar year. Subscribers starting during any given year will be sent back numbers to the first of that year and will be billed for the ensuing year the following January. Make checks or money orders pay. able to The Regents of The University of California; send payment with order to Agricultural Publications at above address. 